\title{
Recurrent Metabolic Acidosis during High-dose Midazolam Therapy for Refractory Status Epilepticus
}

\author{
Shalendra Singh, Ankur Khandelwal, Rashmi Datta', Ashutosh Kaushal, Gyaninder Pal Singh \\ Department of Neuroanaesthesia, AllMS, 'Department of Anaesthesia, Base Hospital, New Delhi, India
}

\section{Abstract}

High-dose continuous midazolam therapy has been used successfully for control of refractory status epilepticus. However, normal anion gap (AG) metabolic acidosis, a deleterious complication of this therapy is underrecognized. Even though previously reported in an isolated case report in a pediatric patient, we observed similar complication in an adult patient. Stereotyped normal AG metabolic acidosis along with hypotension developed on two occasions during high-dose continuous midazolam hydrochloride infusion that reverted rapidly following cessation of the infusion.

Keywords: Acidosis, hydrochloric acid, midazolam, seizures

\section{INTRODUCTION}

Different antiepileptic drugs (AEDs) have been employed alone or in combinations to achieve adequate control for refractory seizure. Midazolam, because of its versatile pharmacologic profile has been used successfully in high dose as continuous infusion for treatment of refractory status epilepticus. ${ }^{[1,2]}$ However, the association of high-dose midazolam infusion and metabolic acidosis is often belittled. Failure to recognize this complication heralds fatal prognosis. We encountered a similar scenario, in which stereotyped severe metabolic acidosis developed on two occasions during high-dose midazolam infusion.

\section{Case Report}

A 21 -year-old $(61 \mathrm{~kg}, 175 \mathrm{~cm})$ male patient arrived in the emergency department in altered sensorium following an episode of status epilepticus. Glasgow Coma Scale score on admission was 8 (E2V1M5). Initial resuscitation involved intubation of trachea, maintenance of ventilatory and circulatory parameters. The patient was a known case of epilepsy for the past 8 years and had been on multiple AED (phenytoin, levetiracetam, and clonazepam). The patient also had a history of uneventful surgery of intracranial electrode implantation a year ago.

\begin{tabular}{|l|l|}
\hline \multicolumn{3}{|c|}{ Access this article online } \\
\hline Quick Response Code: & Website: \\
\hline & www.ijccm.org \\
\cline { 2 - 2 } & \\
\hline
\end{tabular}

Due to ongoing seizure even after starting intravenous (IV) phenytoin, levetiracetam, clonazepam, and phenobarbitone, IV sodium thiopental infusion $(0.5-4 \mathrm{mg} / \mathrm{kg} / \mathrm{h})$ was commenced as per the guideline. Continuous electroencephalographic (EEG) monitoring was also done. On the $3^{\text {rd }}$ day of hospital admission, the patient underwent craniotomy surgery for resection of epileptogenic foci. All the drugs which the patient had been taking preoperatively were started again in the postoperative period. However, clinical seizure (5-6 episodes/day) continued in the postoperative period along with continuous EEG evidence of ictal activity. As such, due to refractory status epilepticus, IV midazolam (midazolam hydrochloride $1 \%+$ benzyl alcohol $1 \%$ ) was started as continuous infusion at a rate of $120 \mathrm{mg} / \mathrm{h}$ on the $12^{\text {th }}$ day of admission. However, after $24 \mathrm{~h}$, the patient developed severe hyperchloremic normal anion gap (AG) metabolic acidosis (nonresponsive to IV sodium bicarbonate). It was associated with hypotension (more than $20 \%$ of baseline) which required low-dose norepinephrine IV infusion ( $1 \mathrm{mcg} / \mathrm{min})$. Plasma levels of AED came to be normal. All other causes of normal AG metabolic acidosis were excluded. Suspecting midazolam to be the cause of this severe

Address for correspondence: Dr. Shalendra Singh, Senior Resident, Department of Neuroanaesthesia, AllMS,New Delhi, India. E-mail:drsinghafmc@gmail.com

This is an open access article distributed under the terms of the Creative Commons Attribution-NonCommercial-ShareAlike 3.0 License, which allows others to remix, tweak, and build upon the work non-commercially, as long as the author is credited and the new creations are licensed under the identical terms.

For reprints contact: reprints@medknow.com

How to cite this article: Singh S, Khandelwal A, Datta R, Kaushal A, Singh GP. Recurrent metabolic acidosis during high-dose midazolam therapy for refractory status epilepticus. Indian J Crit Care Med 2018;22:119-21. 


\begin{tabular}{|c|c|c|c|c|c|c|c|c|c|c|c|c|}
\hline Incidence & Timing of $A B G$ & $\mathrm{pH}$ & $\mathrm{PCO}_{2}$ & $\mathrm{HCO}_{3}$ & Base deficit & Lactate & $\mathrm{Na}+$ & Cl- & Anion gap & $\mathbf{K}+$ & Urea & Creatinine \\
\hline \multirow[t]{3}{*}{1} & $24 \mathrm{~h}$ after start of midazolam infusion & 7.19 & 20 & 7.9 & -18 & 1.33 & 145 & 121 & 18.5 & 2.4 & 11 & 0.4 \\
\hline & $24 \mathrm{~h}$ after sodium bicarbonate correction & 7.20 & 21 & 8 & -18.1 & 1.22 & 147 & 122 & 19.3 & 2.3 & 12 & 0.5 \\
\hline & $24 \mathrm{~h}$ after stopping midazolam & 7.47 & 25 & 18.1 & -4.1 & 1.1 & 145 & 113 & 17.7 & 3.8 & 19 & 0.6 \\
\hline \multirow[t]{2}{*}{2} & $24 \mathrm{~h}$ after start of midazolam infusion & 7.21 & 18.8 & 7.5 & -18.4 & 1.15 & 141 & 119 & 18.2 & 3.7 & 18 & 0.5 \\
\hline & 24-36 $\mathrm{h}$ after stopping midazolam & 7.38 & 29.7 & 17.3 & -6.7 & 0.99 & 143 & 112 & 17.6 & 3.9 & 14 & 0.5 \\
\hline
\end{tabular}

ABG: Arterial blood gas

metabolic acidosis, it was stopped, and IV ketamine ( $2 \mathrm{mg}$ / $\mathrm{kg} / \mathrm{h}$ ) was started. In next $24 \mathrm{~h}$, the acidosis resolved and sodium bicarbonate level assumed near normal levels.[Table 1]. Norepinephrine was tapered and stopped after achieving desired hemodynamics. Since the clinical seizure frequency increased (10-12 episodes/day) as compared to before, the patient eventually underwent right hemispherectomy surgery under general anesthesia.

Next 8 days following hemispherectomy, the patient continued to be asymptomatic. However, yet again, the patient developed intractable seizures on the $9^{\text {th }}$ day after hemispherectomy. IV midazolam $100 \mathrm{mg} / \mathrm{h}$ infusion was started again along with the continuation of other AED. In next $24 \mathrm{~h}$, the patient again developed severe normal AG metabolic acidosis along with fall in blood pressure within $20 \%$ of baseline. Midazolam infusion was stopped and replaced again with ketamine infusion. Yet again, the metabolic acidosis resolved in the next $12 \mathrm{~h}$ following cessation of midazolam infusion [Table 1]. The patient underwent percutaneous tracheostomy due to prolonged ventilation on the $12^{\text {th }}$ day and weaning done in few days with no complication and rest of the patient's hospital stay was uneventful. This time too, high-dose midazolam infusion was linked to metabolic acidosis as a diagnosis of exclusion of other causes of normal AG metabolic acidosis.

\section{DISCUSSION}

Promising results have been shown with the use of high-dose IV midazolam for the treatment of refractory status epileptics both in adults ${ }^{[1]}$ and children. ${ }^{[2]}$ Its water-soluble property decreases venous irritation and its lipophilic property at physiological $\mathrm{pH}$ accounts for its rapid onset of action. ${ }^{[3]}$ Prolonged infusion of other benzodiazepine drugs such as diazepam and lorazepam is not advisable because of the inherent risk of propylene glycol (solvent) toxicity. ${ }^{[4]}$ Refractory metabolic acidosis as a complication of high-dose midazolam infusion has been previously reported in pediatric status epilepticus. ${ }^{[5]}$ However, this association in adults has not been reported. Conventionally, midazolam is used in intensive care units for sedation in adults in doses ranging from 2 to $5 \mathrm{mg} / \mathrm{h} \cdot{ }^{[6]}$ However, in our case, due to epilepsy syndrome, high-dose midazolam infusion (up to $2 \mathrm{mg} / \mathrm{kg} / \mathrm{h}$ ) was used. Normal AG metabolic acidosis that developed on two occasions in our patient during midazolam infusion were stereotyped and reverted after cessation of infusion. Moreover, since no other cause could be found to cause hyperchloremic acidosis in our patient, we speculated that the most probable cause was due to high-dose midazolam therapy.

Unlike diazepam or lorazepam, midazolam is prepared with hydrochloric acid $(\mathrm{HCl})$ to achieve required solubility. In addition, $1 \%$ benzyl alcohol is added as a preservative. Benzyl alcohol toxicity has been associated with high AG metabolic acidosis. ${ }^{[7]}$ However, in our case, the metabolic acidosis was associated with normal AG during both situations, and thus, benzyl alcohol toxicity seemed unlikely in our case. Therefore, the normal AG hyperchloremic metabolic acidosis in our case can be most commonly attributed to cumulative exposure to $\mathrm{HCl}$.

During the first episode, hypotension was more than $20 \%$ of baseline and thus required vasopressor (norepinephrine) support. However, hypotension during the second episode (within 20\% of baseline) did not require any vasopressor support. In both situations, blood pressures returned back to its baseline values after stopping midazolam infusion. Even though literature have found a significant association between hyperchloremic metabolic acidosis and acute kidney injury, ${ }^{[8,9]}$ but in our case, neither clinical (urine output) nor laboratory parameters showed any such association. Presumably, this could be due to transient hyperchloremia and its rapid reversibility following the cessation of the offending agent.

\section{Conclusion}

Benzodiazepines are used as first-line drugs for control of acute seizures. Since midazolam is short-acting with less side effects, it is utilized as a continuous infusion for the treatment of refractory status epilepticus. However, normal AG metabolic acidosis and resulting hemodynamic perturbations that accompanies high-dose midazolam infusion should always be borne in mind. Since there is no role of bicarbonate therapy, prompt cessation of infusion and maintenance of hemodynamic parameters are the only remedial measures.

\section{Declaration of patient consent}

The authors certify that they have obtained all appropriate patient consent forms. In the form the patient(s) has/have given his/her/their consent for his/her/their images and other clinical information to be reported in the journal. The patients understand that their names and initials will not be published and due efforts will be made to conceal their identity, but anonymity cannot be guaranteed. 


\section{Financial support and sponsorship}

Nil.

\section{Conflicts of interest}

There are no conflicts of interest.

\section{RefEREnCES}

1. Fernandez A, Lantigua H, Lesch C, Shao B, Foreman B, Schmidt JM, et al. High-dose midazolam infusion for refractory status epilepticus. Neurology 2014;82:359-65.

2. Morrison G, Gibbons E, Whitehouse WP. High-dose midazolam therapy for refractory status epilepticus in children. Intensive Care Med 2006;32:2070-6.

3. Reves JG, Fragen RJ, Vinik HR, Greenblatt DJ. Midazolam: Pharmacology and uses. Anesthesiology 1985;62:310-24.

4. Wilson KC, Reardon C, Theodore AC, Farber HW. Propylene glycol toxicity: A severe iatrogenic illness in ICU patients receiving IV benzodiazepines: A case series and prospective, observational pilot study. Chest 2005;128:1674-81.

5. Federman MD, Kelly R, Harrison RE. Refractory metabolic acidosis as a complication of high-dose midazolam infusion for pediatric status epilepticus. Clin Neuropharmacol 2009;32:340-1.

6. Ulvi H, Yoldas $\mathrm{T}$, Müngen B, Yigiter R. Continuous infusion of midazolam in the treatment of refractory generalized convulsive status epilepticus. Neurol Sci 2002;23:177-82.

7. Brown WJ, Buist NR, Gipson HT, Huston RK, Kennaway NG. Fatal benzyl alcohol poisoning in a neonatal Intensive Care Unit. Lancet 1982;1:1250.

8. Yunos NM, Bellomo R, Hegarty C, Story D, Ho L, Bailey M, et al. Association between a chloride-liberal vs. chloride-restrictive intravenous fluid administration strategy and kidney injury in critically ill adults. JAMA 2012;308:1566-72.

9. McCluskey SA, Karkouti K, Wijeysundera D, Minkovich L, Tait G, Beattie WS, et al. Hyperchloremia after noncardiac surgery is independently associated with increased morbidity and mortality: A propensity-matched cohort study. Anesth Analg 2013;117:412-21. 